\title{
Research on Expansive Learning Model Design in E-schoolbag Environment
}

\author{
Xiao-xiao DONG and Hong-hua WANG
}

School of Information Science and Technology, Northeast Normal University, Changchun, Jilin, China

Keywords: E-schoolbag, Expansive learning, Model.

\begin{abstract}
With the rapid development of education informationization, our country's education informationization has stepped into the stage of effectively supporting teaching and learning and promoting the individualized development of students. Engeström, the founder of the Third Generation Theory of Activity, puts forward the concept of expansive learning which aims at cultivating the ability of group innovation in line with the core pursuit of cultivating creative talents by educational informationization. However, its lack of impact on technical environments concern. E-schoolbag as a support environment, how to use e-schoolbag to build such an environment, how to design teaching activities so far there is no good solution. Therefore, this study first redefines the cognitive perspective of e-schoolbag environment based on the literature research, and then designs for the extension of learning in the environment of e-schoolbag. Finally, it designs the case study of e-learning based on e-schoolbag. In the transformation of the traditional teaching model to promote the effective implementation of teaching activities for the current practice of education to contribute a meager contribution to the strength.
\end{abstract}

\section{Problem Statement}

In recent years, our country has made rapid progress in education informatization. "National Medium and Long-Term Education Reform and Development Plan (2010-2020)" pointed out that "establishing a diverse concept of talent, respecting individual choices, encouraging individual development, and cultivating qualified personnel in an eclectic manner" ${ }^{[1]}$.The "Ten-year Development Plan of Education Informationization (2011-2020)" proposed in the framework of the development level of basic education informatization that the reform of school education and teaching methods should make breakthroughs in the changes of student diversity and individualized learning ${ }^{[2]}$. As can be seen from the national policy, to promote the individual development of learners and to cultivate innovative talents are the core pursuit of the development of education informatization at this stage.

Finland scholar Engeström's expansive learning theory precisely aims to cultivate group innovation ability, which is in line with the core pursuit of education informationization for innovative personnel training. However, this theory does not pay special attention to the influence of technical environment on activities How to design the technical environment so far are not yet clear. The "Ten-year Development Plan for Education Informationization (2010-2020)" explicitly proposed to "promote the integration of information technology and teaching, build an intelligent teaching environment, provide high-quality digital educational resources and software tools, and use information technology to carry out heuristics and explore Bridging the Digital Divide in Basic Education "by discussing, engaging, and encouraging developmental evaluations" ${ }^{[2]}$.As a new medium emerging in the process of educational informationization, e-schoolbag can be used as a supportive environment. The core idea of its development is personalization, mobility, on-demand services, and the use of cloud to provide resources, tools and services to build a Almost "all-around" personal learning environment ${ }^{[3]}$. However, domestic scholars have not come up with good research ideas on such issues as how to use e-school bags to build such an environment, how to design teaching activities, how to promote effective teaching, how to change traditional teaching methods and how to cultivate creative talents. 


\section{Expansive Learning Theory and Overall Design Ideas}

The theory and concept of extended learning was first proposed by the Finland scholar Engeström in 1987 by "Expanding Learning: A Theoretical Approach to Activity-Oriented Development Studies" Simple ideas expand into a complex activity goal or form a new form of practice (Engeström, 2008) ${ }^{[4]}$. Engeström also proposed a cycle of extended learning, called Expansive Cycle: "Question - Analysis - Modeling - Testing a New Model - Implementation of the new model - reflection and evaluation - to consolidate the new practice "seven steps (see Figure 1 below) ${ }^{[5]}$.

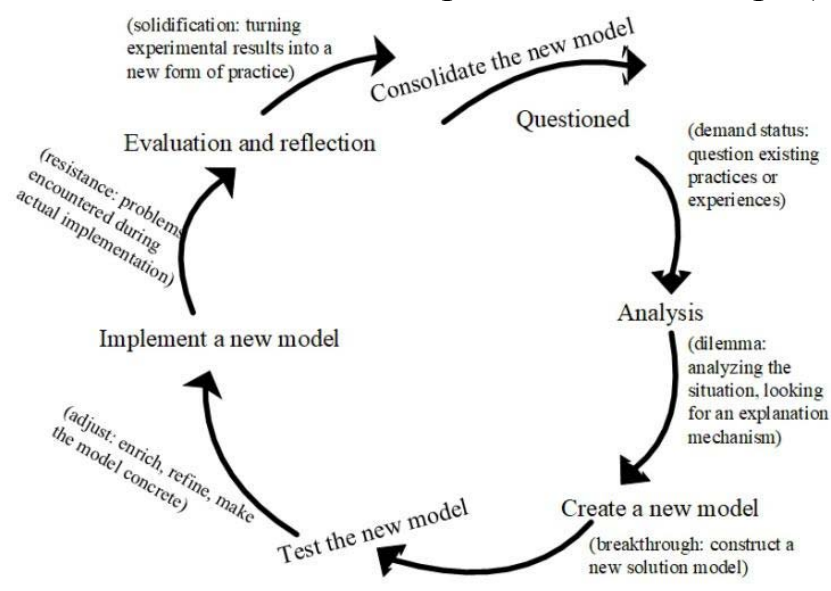

Figure 1. Expensive learning activity cycle

As a supportive environment, e-schoolbag currently focuses on five areas: introduction of products, application of technology, design and development, current situation and reflection, as well as prospects of the future, especially for technology and applications, focusing on technology-level design But the lack of education and teaching considerations ${ }^{[6]}$.Therefore, this study firstly focuses on the new level of awareness of e-schoolbag in the education and teaching functions, then designs the e-schoolbag based on the complete expansive cycle, and then designs the expansive learning application case based on e-schoolbag. In this way, we can make some demonstration on the design model of extended learning in e-schoolbag environment. Specific style of thinking is shown in Figure 2 below:

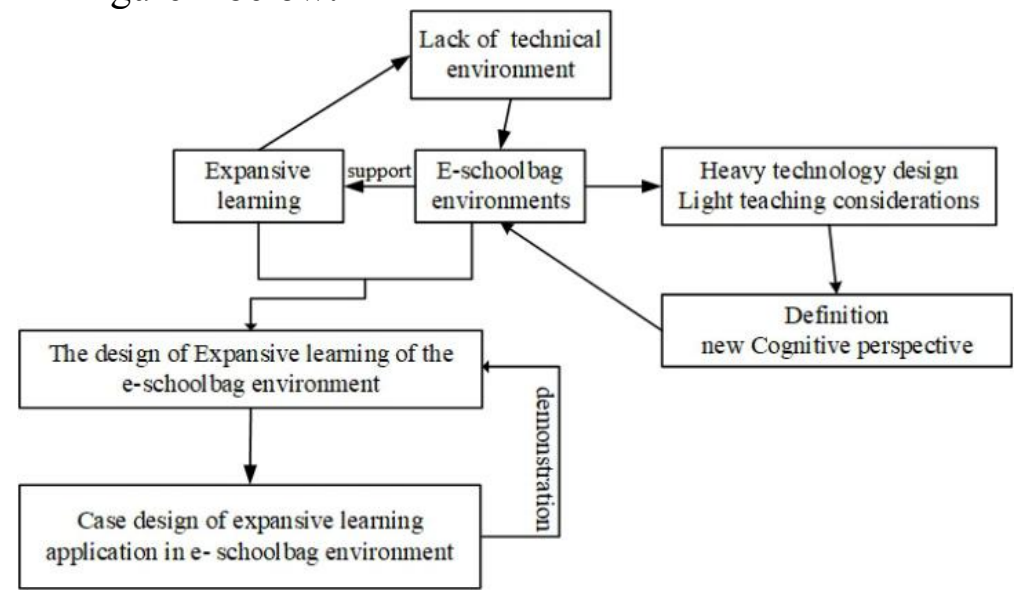

Figure 2. Overall idea

\section{Based on the E-schoolbag Environment to Expansive Learning Model Design New Definition of E-schoolbag Environmental Cognition}

For e-schoolbag, there is no clear and unified understanding of the gap between the domestic and foreign. Foreign scholars mainly focus on the "virtual" learning space of e-schoolbags. The following two views exist: First, "e-schoolbags are a computer-supported digital collaborative 
learning space that uses the Internet as the basis for the environment to support teachers and students, Synchronous or asynchronous exchange and resource sharing "[7]. Second, "E-school bag is a universal network facility that supports informal learning. Students can log in, withdraw from the e-school bag and manage their own digital resources using devices based on technologies such as Bluetooth and wireless networks" ${ }^{[8]}$.The domestic research on e-schoolbag focuses on the "real" equipment level. For example, Xie Zhongxin, Shanghai Institute of Educational Development, Pudong New Area, believes that "e-schoolbag" actually constructs a digital learning environment consisting of learning content, Terminal and service platform consists of three parts ${ }^{[9]}$, East China Normal University, Zhu Zhiting, Yu Xiaohua and other scholars will also think of e-schoolbags as a learning environment, advocating equipment, content and services from the perspective of the three fusion design ${ }^{[3]}$. Therefore, based on the integration of the three cognitive perspectives of equipment, content and resources, Yu Xiaohua of East China Normal University, based on the integration of e-schoolbag design and the interactive perspective embodying the function of education and teaching, as shown in Figure 3 below.

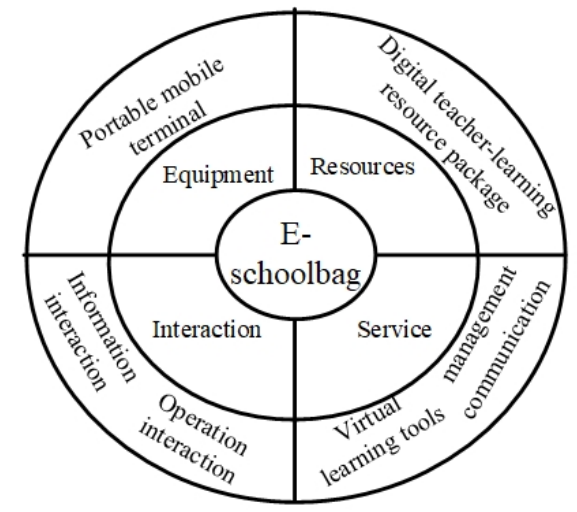

Figure 3. E-schoolbag environmental cognitive perspective of a new definition

\section{Based on the Environment of the E-schoolbag Expansive Learning Model Design}

Based on the complete cycle of expansive learning activities, this module builds an expansive learning model based on the environment of the e-schoolbag from the cognitive perspective of the e-schoolbag environment, as shown in Figure 4 below.

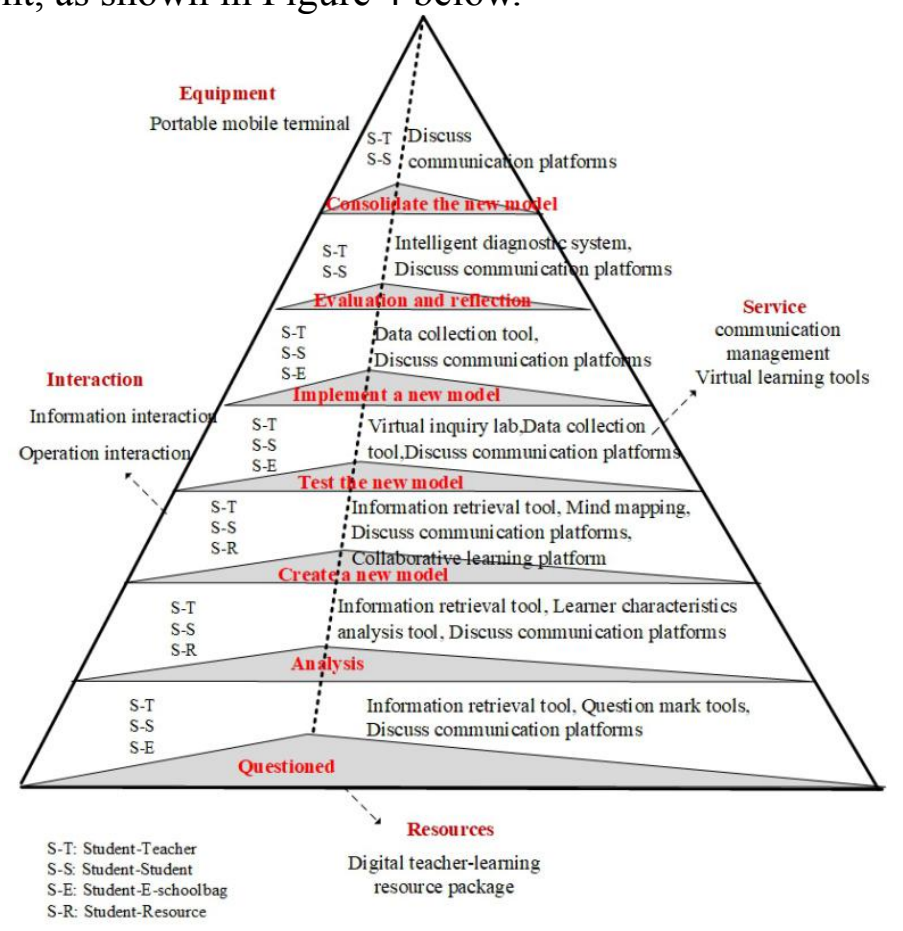

Figure 4. Extended learning model based on e-book environment 
Questioned. Questioning stage is the first step in expansive learning. In the questioning stage, when learners question the existing concepts or experiences, they can first use the question markup tool to ask questions and mark the questions, and then read the learning materials provided in the resource library or use the information search tool in the network resources In the retrieval of the required information on the question in the discussion exchange platform for discussion and exchange, seeking answers.

Analysis. The analysis phase is the second step of expansive learning, analyzing the causes of questioning and seeking the explanation mechanism of the question. In the analysis stage, learners can first access the local knowledge base of the e-schoolbag or use the information search tool to search related resources in the network resources and share and exchange the needed resources. At the same time, the learner analysis tool in the e-schoolbag will learn about the learning the characteristics of the analysis, based on the principle of heterogeneous grouping freely into a learning group, forming a learning community between students, teachers and students.

Create a New Model. After analyzing the existing problems, the new model stage is to build a new model of the latest interpretation in public cognition. At this stage, teachers and learners first discuss the task together to arrange the learning tasks and distribute them to each learning group. According to specific tasks, each learning group can browse the local knowledge base in the e-book package or use the information searching tool in the network resource library In the search for resources needed for exchange and sharing, and then use the mind map learners individual or study group invisible knowledge or idea of explicit expression, the construction results will be displayed to other members to facilitate learners to learn different in the collaborative learning platform to achieve the depth of interaction point of view, to enhance the depth of thinking of learners.

Test the New Model. After creating a new model, we need to test the new model by trying out the model, grasping its dynamics and effectiveness. In testing the new model stage, the learner can place the new model in a virtual simulation lab to simulate the test, collect data using data collection tools and analyze the data, discussing the test results of the new model from the communication platform.

Implement a New Model. After the simulation tests the new model, the new model needs to be verified in the actual situation and the new model implemented in the real situation. The implementation process of this phase is similar to that of the new model test. Learners use data collection tools to collect data and analyze the data. The exchange platform discusses the implementation results of the new model.

Evaluation and Reflection. Evaluation throughout the extended learning process. In the stage of reflection and evaluation, the intelligent diagnosis system will evaluate the learner's learning process and learning results, and form an evaluation report and feedback to the learners and teachers. After that, learners and teachers may reflect on the learning platform and find out Insufficient and improved.

Consolidate the New Model. Consolidation phase is the last step to expand learning. To consolidate the new model is to consolidate the previous phases based on the appropriateness of the existing situation to form a new and stable form of practice and application. This phase is mainly the exchange of learners Characterization of the results after discussion with the discussion platform.

Under the environment of e-schoolbag, the process of extending learning needs to instruct the learners to complete the study through discussion, communication and collaboration under the supervision of the teachers. The teachers 'learning materials management, the guidance and supervision of the learner's learning process and the learners' the formation of personal folders play an important role in the service level.

\section{Conclusion}

Learning is a protracted topic both in academia and in daily life. Faced with the current 
requirements of educational innovation, the emergence of the theory of extended learning provides an effective way to train creative talents, and at the same time it guides the establishment of e-schoolbags in the cognitive perspective of educational and teaching functions. The design of extended learning in the environment of e-schoolbag verifies the influence of technical environment level on expanding teaching activities, assures the integration of information technology and teaching, and promotes the effective development of teaching. While it promotes the individual development of learners, more conducive to shaping the ability of innovative thinking and training of innovative personnel.

\section{Acknowledgement}

This research was financially supported by the Key Techniques and Application Demonstration of Constructing Intelligent Mobile Terminal Teaching Software Platform (Item Number: 20170204001GX).

\section{References}

[1] The Central People's Government of the People's Republic of China. Outline of the National Medium and Long-Term Education Reform and Development Plan (2010-2020) [EB/OL].2010. Http://www.gov.cn/jrzg/2010-07/29 content_1667143.htm, 2014-02-12.

[2] Ministry of Education, People's Republic of China. Education Informationization Ten Years

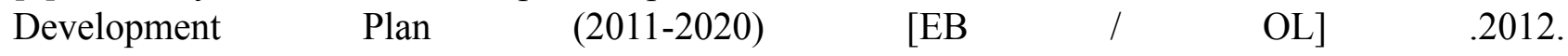
http://www.moe.gov.cn/publicfiles/business/htmlfiles/moe/s3342/201203/xxgk_133322.html, 2014-02-12.

[3] ZHU Zhi-Ting, YU Xiao-Hua.Electronic bag system and its function modeling [J]. Journal of Electrochemistry Education, 2011, (04): 24-27+34.

[4] Engestrom, Y. (2008).From Teams to Knots: Activity Theoretical Studies of Collaboration and Learning at Work [M].Cambridge: Cambridge University press, 100-101.

[5] Engeström,Y. (2009).Expansive learning: Toward an activity-theoretical reconceptualization [J]. In Knud-Illeris (Ed), Contemporary Theories of Learning. Routledge press. 51-73.

[6] Su Xiaoxiao. Design and development of e-book package for extended curriculum [D]. Shanghai Normal University, 2014.

[7] G. Chabert, J.Ch. Marty, B. Caron, T. Caron, L. Vigonllet, C. Ferraris. The Electronic Schoolba g: A CSCW Workspace. Presentation and Evaluation[J]. Al \& Society-AIS, 2006.

[8] Christina Brodersen, Bent G.Christensen, Kai Gronbak, Christian Dindler, et al:e Bag-a Ubiquitous Web Infrastructure for Nomadic Learning[R]. World Wide Web Conference Series-www, 2005.

[9] Xie Zhongxin. "Electronic bag" $\neq$ purely mobile terminal - return to rationality, "e-book package" needs to be clearly defined more [J].Primary and secondary information technology education, 2011(2):15-16. 